\title{
Effect of Variations in Micropatterns and Surface Modulus on Marine Fouling of Engineering Polymers
}

\author{
Agata Maria Brzozowska, ${ }^{\dagger}$ Stan Maassen, ${ }^{\dagger, \dagger}$ Rubayn Goh Zhi Rong, ${ }^{\dagger, \S}$ Peter Imre Benke, ${ }^{\perp, \#}$

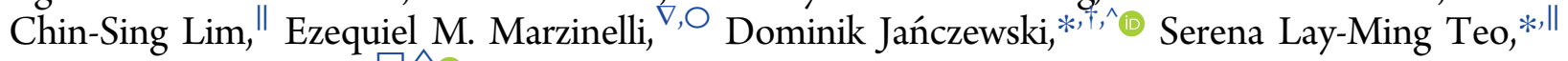 \\ and G. Julius Vancso* $, \square, \diamond$
}

\begin{abstract}
${ }^{\dagger}$ Institute of Materials Research and Engineering, Agency for Science, Technology and Research, 2 Fusionopolis Way, Innovis, \#08-03, 138634 Singapore

${ }^{\ddagger}$ Faculty of Science and Technology, University of Twente, Drienerlolaan 5, 7522 NB Enschede, The Netherlands

${ }^{\S}$ School of Materials Science and Engineering, Nanyang Technological University, 50 Nanyang Avenue, 639798 Singapore

"St John's Island National Marine Laboratory, Tropical Marine Science Institute, National University of Singapore, 18 Kent Ridge Road, 119227 Singapore

${ }^{\perp}$ Singapore Centre on Environmental Life Sciences Engineering, Nanyang Technological University, Singapore, 60 Nanyang Drive, 637551 Singapore

\#Environmental Research Institute, National University of Singapore, 21 Lower Kent Ridge Road, 119077 Singapore

${ }^{\nabla}$ Centre for Marine Bio-Innovation, School of Biological, Earth and Environmental Sciences, University of New South Wales, Sydney, NSW 2052, Australia

OSydney Institute of Marine Science, 19 Chowder Bay Rd, Mosman, NSW 2088, Australia

^Laboratory of Technological Processes, Faculty of Chemistry, Warsaw University of Technology, Noakowskiego 3, 00-664 Warsaw, Poland

$\square$ Institute of Chemical and Engineering Sciences, Agency for Science, Technology and Research, 1 Pesek Road, 627833 Singapore

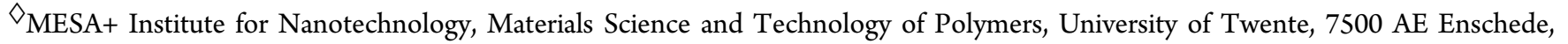
The Netherlands
\end{abstract}

\section{Supporting Information}

ABSTRACT: We report on the marine fouling and fouling release effects caused by variations of surface mechanical properties and microtopography of engineering polymers. Polymeric materials were covered with hierarchical micromolded topographical patterns inspired by the shell of the marine decapod crab Myomenippe hardwickii. These micropatterned surfaces were deployed in field static immersion tests. PDMS, polyurethane, and PMMA surfaces with higher elastic modulus and hardness were found to accumulate more fouling and exhibited poor fouling release properties. The results indicate interplay between surface mechanical properties and microtopography on antifouling performance.

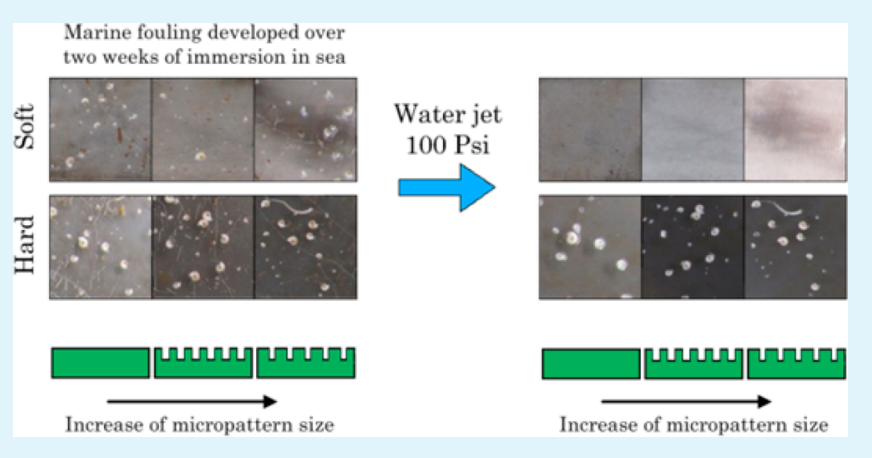

KEYWORDS: surface patterning, biofouling, PDMS, polyurethane, poly(methyl methacrylate), surface properties

\section{INTRODUCTION}

Marine biofouling is an extensively studied problem that affects the maritime and offshore industries. ${ }^{1-3}$ Despite many approaches to control marine fouling, ${ }^{4,5}$ limitations in available materials and problems with available antifouling coatings such as toxicity, ${ }^{6}$ durability, ease of application or costs of application, and the maintenance of the antifouling/foulingrelease coatings ${ }^{7}$ are still of great concern. There is a pressing need to develop durable, nontoxic materials that can be easily applied and enable more than one mechanism of antifouling action. Biomimetic approaches as strategies inspired by nature (naturally antifouling objects) have attracted broad attention to achieve these goals. ${ }^{8-10}$ In our ongoing research we explore natural antifouling surfaces and use them as an inspiration in our materials design to obtain antifouling surfaces of enhanced performance. ${ }^{11}$ Model systems must then be replicated with industrially relevant polymers for commercialization.

Received: November 25, 2016

Accepted: $\quad$ May 8, 2017

Published: May 8, 2017 
Susceptibility to colonization by aquatic organisms is affected by properties of the immersed materials. ${ }^{12}$ These include physicochemical properties, like chemical composition (exposed functional groups), surface charge, wettability, surface free energy, roughness, ${ }^{13}$ as well as surface mechanical properties, i.e., elastic modulus. ${ }^{14,15}$ Modification of these properties allows one to modulate fouling accumulation on surfaces. Such an approach may be applied in the form of chemically active coatings, containing biocides or enzymes, or nontoxic coatings in form of engineered microtopographies and fouling release materials. ${ }^{7}$ The former slowly discharge biologically active compounds into the water column typically affecting not only the attached organisms but also the nonfouling organisms in the vicinity of the coated vessel (or other objects). ${ }^{6,16}$ The latter allows for a deposition and growth of biological materials up to a certain threshold. Upon reaching this threshold, the combination of the material properties and external forces (e.g., shear) results in a fracture of the bonding between the deposited biomaterial and the substrate, leading to the peel-off of the deposited biomass. The critical force necessary to initiate this fracture correlates with surface energy and elastic modulus of the material. ${ }^{7,17}$ The main disadvantages of the fouling release coatings are that (i) they exhibit a limited mechanical robustness, as the coatings with the desired (low) surface energy are mostly silicone-based, and (ii) they require the use of an external force for the detachment of the accumulated biomass; that is, such coatings may not be effective when applied onto stationary objects. Thus, there is an ongoing effort to develop alternative methods for the modification of surface properties to minimize the adhesion of biomass and to promote detachment of biomass under low or no shear conditions. ${ }^{14,18-21}$ Surface roughness plays a crucial role in fouling, ${ }^{22-24}$ and depending on the length scale of the surface features, it can either facilitate (mechanical interlocking) or suppress the adhesion and subsequent settlement of fouling organisms.

In our work we investigate surfaces featuring hierarchical micropatterns, inspired by naturally occurring fouling-free surfaces of the decapod crab Myomenippe hardwickii. As described in detail in our previous paper, ${ }^{11}$ this particular species was selected as their carapace remains relatively free of fouling despite their occurrence in shallow water biofouling communities on artificial structures where burrowing behavior cannot occur. It is known that antifouling properties of natural surfaces cannot be attributed to a single surface characteristic but are likely the result of a combination of surface topography and extracellular excretions, i.e., enzymes. In earlier work we proposed a combination of physical and chemical modifications of silicone-based polymeric substrates designed to improve their antifouling properties. ${ }^{11}$ This previous work encompassed the use of polydimethylsiloxane (PDMS), which allowed easy and accurate replication of patterns with various aspect ratios features, and also enabled uncomplicated chemical surface modification. ${ }^{11}$ PDMS possesses low surface energy and low surface modulus, and as such it has become a commonly used material in model laboratory antifouling studies. However, this relatively soft material has limited mechanical robustness (e.g., shear strength) in a pure form. ${ }^{25,26}$ Thus, in this study, we extend our earlier concept to nonsilicon-based materials, namely polyurethane (PU) and poly(methyl methacrylate) (PMMA). Polyurethanes have been the subject of antifouling studies as discussed, e.g., by Cooksey et al. ${ }^{2}$ These are commonly used in various forms: (i) resins (coatings, adhesives, sealants and elastomers, CASE), (ii) flexible foam (linings), (iii) rigid form (insulation), and (iv) thermoplastic (cables coatings, tubing, drive wheels, etc.). ${ }^{27}$ PMMA is used, among others, to fabricate transparent parts of underwater equipment, structural panels, aquaria, worktops, as well as in various biomedical applications. ${ }^{28}$ Both materials are relevant for the maritime industry.

In this work we focused on the effect of the mechanical properties of these materials in relation to the antifouling performance of smooth and patterned samples. As observed earlier, it is likely that combination of the "most efficient" surface roughness, surface energy and modulus may reduce the fouling potential of the surface in a synergistic manner. An importance of carefully designed surface micropatterns as components of antifouling solutions has been shown and discussed in literature, ${ }^{24,29-34}$ with Sharklet being one of the most prominent examples. Here, we study a different topography, which includes features at two different length scales. We also vary the size of the patterned features, e.g., the effects of 3 or $5-\mu \mathrm{m}$-diameter pillars are investigated. We show that complex 3D patterning with hierarchical microstructures can be achieved in PU and PMMA and demonstrate how changes in modulus and hardness contribute to fouling accumulation under natural field conditions.

\section{MATERIALS AND METHODS}

A PDMS (Sylgard 184 Silicone Elastomer) kit was purchased from Dow Corning. Poly $\left(4,4^{\prime}\right.$-methylenebis(phenyl isocyanate)-alt-butanediol/dipg/polycaprolactone) and poly(methacrylic acid methyl ester) were purchased from Aldrich. Diodomethane (Sigma-Aldrich, 158429), glycerol (Sigma, G5516), anhydrous hexadecane (SigmaAldrich, 296317) were purchased from Sigma-Aldrich. $1 \mathrm{H}, 1 \mathrm{H}, 2 \mathrm{H}, 2 \mathrm{H}-$ Perfluorodecyltrichlorosilane (FDTS, 96\%) was purchased from Gelest and stored inside a nitrogen-filled glovebox. All chemicals were used as received. Deionized (DI) water $(18 \mathrm{M} \Omega \mathrm{cm})$ and ultrapure nitrogen were used throughout the experiments. Silicon wafers with the thickness of $0.56 \mathrm{~mm}$ and resistivity of 10-20 $\Omega \mathrm{cm}$ were purchased from Latech Scientific Supply Pte. Ltd. (Singapore).

Design and Replication of Surface Patterns. The design of the hierarchical micropatterns was inspired by the surface topography of decapod crustacean, Myomenippe hardwickii. We discussed the statistical characterization of its carapace surface, as well as the pattern design and method of pattern replication in PDMS in our previous work. ${ }^{11}$

Patterned PDMS samples were fabricated applying standard casting procedures. Patterned PMMA and PU samples were fabricated from polymer pellets using hot compression moulding (manual hot press, LabTech Engineering Company Ltd.), according to the following protocol: the silicone molds were coated with vapor deposited FDTS layer and placed within a metal frame lined with a fluorinated film (see Figure S1 in the Supporting Information). Subsequently, the polymer pellets were placed on the patterned moulds and then placed between the hot press plates heated up to the polymer melting temperature. Once the pellets softened, the frame with the samples was covered with another sheet of the fluorinated film, and the second metal plate was placed on the top. Following several compression and decompression cycles applied in order to remove gas bubbles from the melted polymer, the samples were compressed to $300 \mathrm{psi}$ and later to $500 \mathrm{psi}$ for $10 \mathrm{~min}$, respectively, at constant temperature of $190{ }^{\circ} \mathrm{C}$ and $180{ }^{\circ} \mathrm{C}$ for PMMA and PU, respectively. An example of the resulting sample is shown in Figure S2 in Supporting Information. Subsequently, the polymer samples with the replicated patterns were removed from the moulds. The demoulding of PU took place at room temperature, and the demoulding of PMMA was performed at $150{ }^{\circ} \mathrm{C}$ to prevent damaging the moulds due to the PMMA shrinkage upon cooling. The de-moulded samples were then cleaned with water. Due to technical difficulties in pattern replication in PMMA, we obtained a 


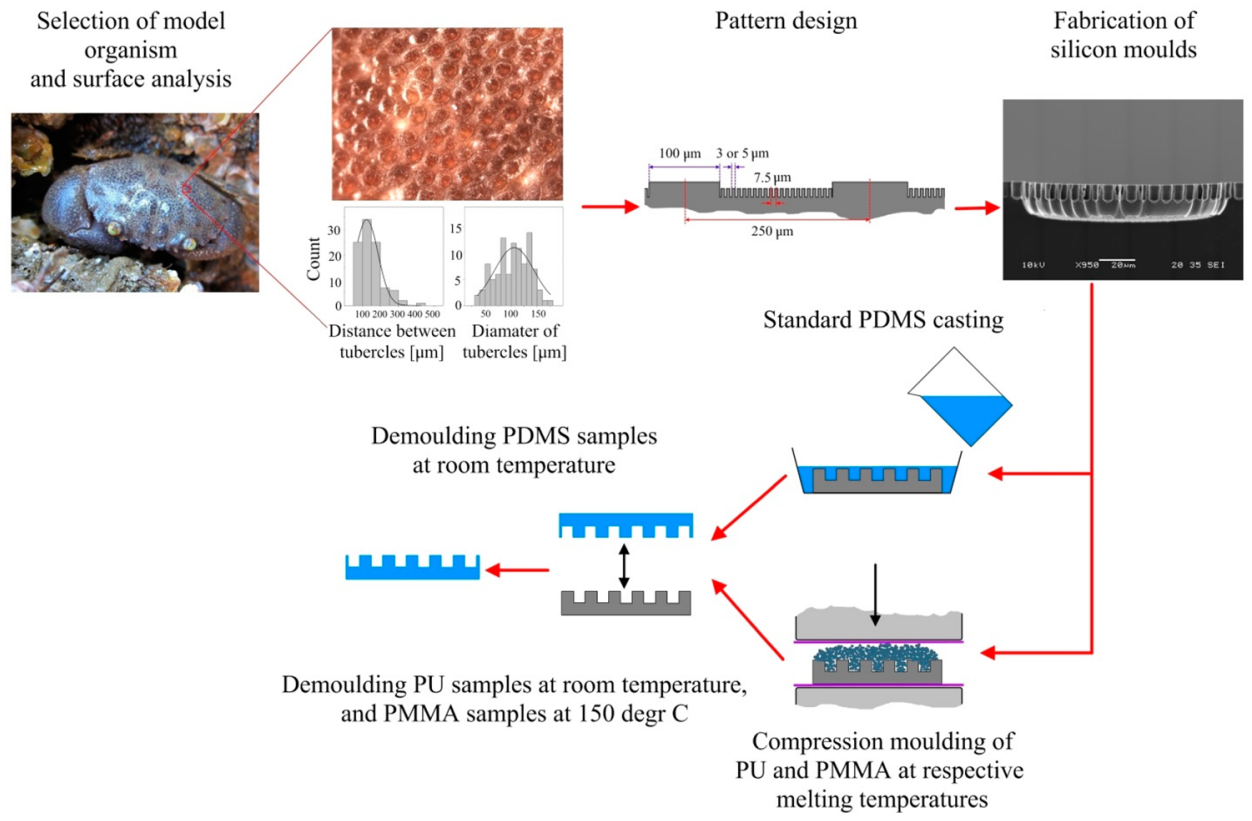

Figure 1. Schematic representation of the surface engineering process described in the text.
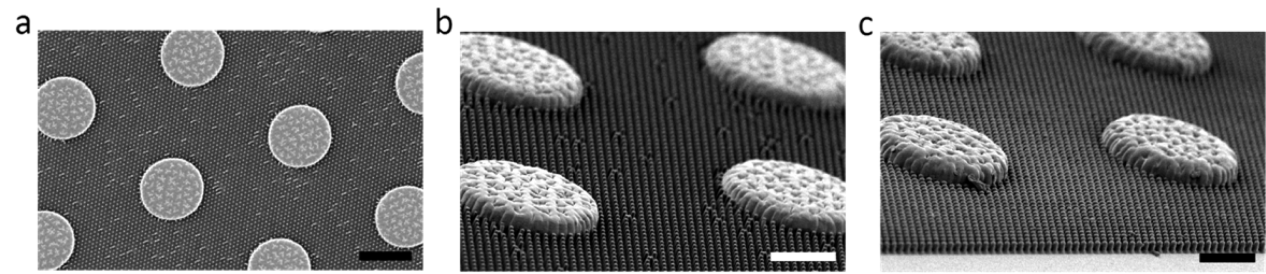

Figure 2. Hierarchical surface patterns, inspired by the carapace surfaces of marine decapod crab Myomenippe hardwickii, consisting of two overlapping hexagonal arrays of $100 \mu \mathrm{m}$ cylinders and $3 \mu \mathrm{m}(\mathrm{a}, \mathrm{b})$ and $5 \mu \mathrm{m}$ diameter pillars (c), respectively, reproduced in PU using compression molding. The scale bars correspond to 100 (a), 50 (b), and $50 \mu \mathrm{m}$ (c), respectively.
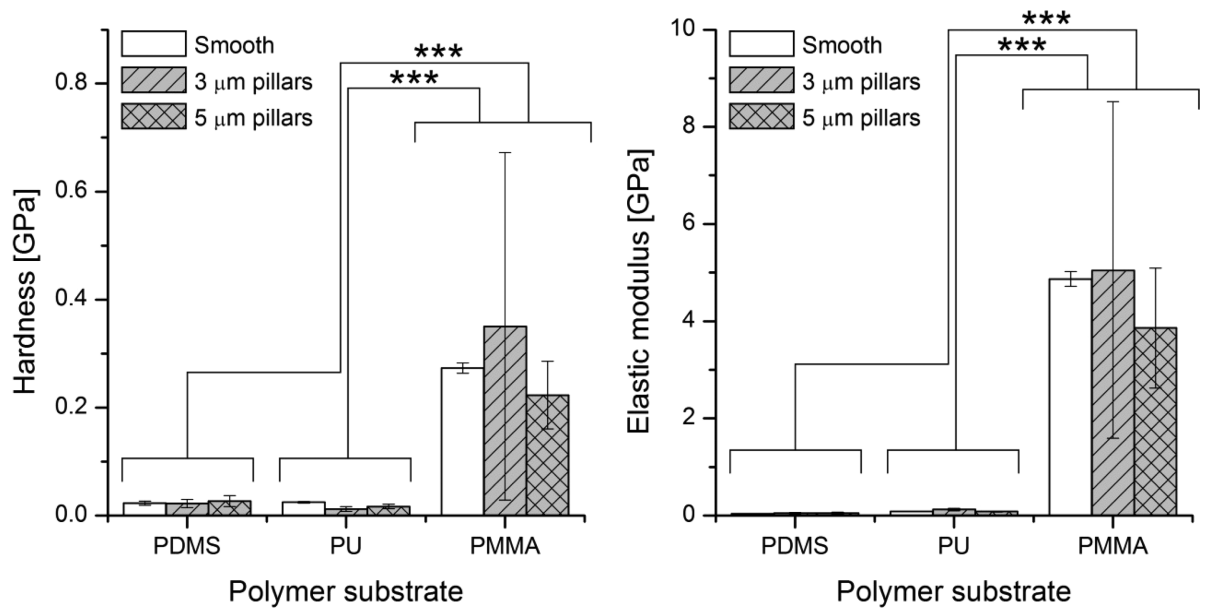

Figure 3. Hardness (left) and elastic modulus (right; means \pm SD) of the smooth and patterned polymer substrates discussed in this study. We marked significant differences between samples ('***’ $p<0.001)$.

limited number of samples of sufficient quality. Thus, only PMMA samples with $5 \mu \mathrm{m}$ pillars were tested as a single replicate only. The process of fabrication is schematically shown in Figure 1, and the examples of the resulting patterned surfaces are shown in Figure 2.

Surface Characterization. Static and dynamic contact angle measurements for the determination of surface energy and critical surface tension were carried out using a VCA Optima apparatus (AST products, Inc.). Each sample was tested in four replicates for each liquid, namely: water, methyl iodide, glycerol, and $n$-hexadecane. Four different areas were tested on each replicate. Surface hardness and surface elastic modulus were determined using an Agilent G200 Nanoindentation System.

To determine an appropriate load to apply during nanoindentation measurements, we considered data for the larvae of a well-studied fouling model organism, the barnacle cyprid. During surface explorations, a barnacle exerts force onto the substrate in a "bipedal walking" during "stepping down" onto the surface and "stepping off" from the surface. A force exerted during pulling the antennules of the 
larva away from the surface is larger as the residues of the temporary adhesive released by the cyprid increase strength of its attachment to the surface. These antennule pull-off forces have been estimated using B. balanoides cyprid to range from $0.66 \times 10-5 \mathrm{~N} / \mathrm{m}^{2}$ to $1.70 \times 10-5$ $\mathrm{N} / \mathrm{m}^{2}$ on beeswax and polyvinyl chloride, respectively, ${ }^{35}$ and were in the range of $0.41 \pm 0.2 \mathrm{nN}$ using colloidal probe AFM experiments. ${ }^{36}$ The load applied during the mechanical tests (nanoindentation) was $0.5 \mathrm{mN}$ for all tested materials. Thus, as compared to the results shown in Figure 3, we assume that the exploring organisms would not detect significant differences in mechanical properties of smooth and patterned surfaces, that is, for a given polymer, mechanical surface properties may not be the main factor governing fouling by this species. On the other hand, the differences between mechanical properties of "soft" PU and PDMS, and "hard" PMMA may be significant enough to affect settlement. Tubeworm larvae also contact surfaces during exploration and attachment, ${ }^{37}$ although the mechanism of these behaviors are as yet poorly described. We tested the hypothesis in the field tests. During the indentation measurements, a probe was pressed against parts of a surface covered with arrays of 3 and $5 \mu \mathrm{m}$ pillars, respectively. The contact area between the surface and the probe is estimated as $24.5 \times$ (displacement), ${ }^{2}$ and on average equaled 0.16, 0.06, and $0.002 \mathrm{~m}^{2}$, for PDMS, PU, and PMMA, respectively. As such, during the experiment the force was exerted on a group of pillars rather than on a single pillar. At maximum load the value of the Poisson's ratio was set at 0.4 for each measurement. Each sample was tested in five replicates, and at least ten measurements were performed on each replicate. We report here the arithmetic mean values obtained.

$\zeta$-potential measurements were performed using SurPASS Electrokinetic Analyzer (Anton Paar).

Effect on Surface Patterning on Marine Growth. To compare the fouling and fouling release properties of the materials, the samples were deployed in a static field immersion test. The static field immersion tests were carried out off a floating platform in the west coast of Singapore. All samples, except PMMA, were tested in four replicates. The substrates were mounted on PVC 1 " by $3^{\prime \prime}$ slides using nitryl flat washers and stainless steel screws and nuts. After 2 weeks of immersion the samples were subjected to water jet cleaning for fouling removal at 50 and $100 \mathrm{psi}$, at a distance of $50 \mathrm{~mm}$. The total organisms count was recorded before and after water jet cleaning. To investigate the effect of the pattern dimensions $(5 \mu \mathrm{m}+100 \mu \mathrm{m}$ hierarchical structures vs $3 \mu \mathrm{m}+100 \mu \mathrm{m}$ hierarchical structures) on fouling removal, after two weeks immersion, samples were raised and subjected to the water jet cleaning of varying water pressure. ${ }^{7}$ The cleaned samples were immersed again (second immersion) in seawater in order to assess the effect of the residual biomass (biomass not removed from the substrates during the water jet cleaning) on the subsequent fouling. The samples were returned to the field after water jet cleaning for the duration of two additional weeks, followed by the fouling release test under the same conditions as after the first immersion.

Data Analysis. The effect of surface modification on the number of organisms settled during field tests was analyzed using the multiway analysis of variance (ANOVA; $\alpha=0.05$ ) method. For significant terms in ANOVA with more than two levels, posthoc Tukey's multiple comparisons were used to determine which treatments were different. The assumptions of homogeneity of variances and normality were assessed during Barlett and Shapiro-Wilk tests, respectively. When the necessary assumptions were not met and transformation of data was not appropriate, analyses were still carried out as multiway ANOVAs are robust to departures of these assumptions, particularly when the sample size was large $(N>30) .{ }^{38}$ All statistical tests were performed using the R (Development Core Team, 2010) software package.

\section{RESULTS AND DISCUSSION}

The protocol for pattern design and fabrication is based on our previous work with details of the process not discussed here in depth. ${ }^{11}$ In short, following statistical analysis of carapace surfaces of marine decapod crab Myomenippe hardwickii, we proposed a design of hierarchical micropattern consisting of two overlapping hexagonal arrays of cylindrical structures of different aspect ratios. The first array consists of 3 or $5-\mu \mathrm{m}$ diameter pillars, $10 \mu \mathrm{m}$ high, with a distance of $7.5 \mu \mathrm{m}$ between their centers. The second array consists of $100-\mu \mathrm{m}$-diameter pillars, $20 \mu \mathrm{m}$ high, with a distance of $250 \mu \mathrm{m}$ between their centers. The selected dimensions of the small structures are relevant for understanding the exploratory behavior of fouling species. Most benthic microalgal cells occur in sizes ranging from 5 to $20 \mu \mathrm{m}$. While invertebrate larvae may be $>100 \mu \mathrm{m}$ in body size, their sensory appendages are much smaller, and it is likely that they can discriminate between micron size roughness. Not much is known about the exploratory behavior of tubeworm larvae except that physical contact with the surface and biofilms is necessary. The summary of the patterns development and replication is shown in Figure 1. Examples of the patterns with 3 and 5- $\mu \mathrm{m}$-diameter pillars replicated in PU are shown in Figure 2.

We reproduced the designer patterns in PDMS and used the corresponding specimens in the present study as reference material. For fabrication the standard casting method developed previously was used. Eleven patterns replicated in two other polymers, namely PU and PMMA, were fabricated using hot compression moulding, as described in the Materials and Methods section. Selected properties of PU and PMMA, relevant to this study, are summarized in Table 1.

Table 1. Selected Properties of the Polymers Used in This Study

\begin{tabular}{lllc} 
& \multicolumn{1}{c}{ PDMS } & \multicolumn{1}{c}{ PU } & PMMA \\
modulus [GPa] & $3.8 \times 10^{-2 a}$ & $8.5 \times 10^{-2}$ & 4.87 \\
water contact angle $[\mathrm{deg}]$ & 114.7 & 105.9 & 96.4 \\
surface energy $[\mathrm{mN} / \mathrm{m}]$ & & 22.3 & 26.7 \\
critical surface tension $[\mathrm{mN} / \mathrm{m}]$ & 23.4 & 23.9 & 20.8 \\
isoelectric point & 4.25 & 4.10 & $4.2^{39}$
\end{tabular}

${ }^{a}$ The elastic modulus values of PDMS determined in this study carry significant uncertainty due to sample deformation upon indentation, which is not accounted for during raw data fitting, and should be viewed as a value for a rough indication only.

The impact of the surface energy and polarity (wettability) on marine fouling performance of various materials has been broadly discussed in the literature. ${ }^{40-43}$ Although the problem remains controversial, research suggests that the surface energy is important for the determination of the initial settlement of macrofouling organisms, but its long-term influence on the development of biofilms is not clear. ${ }^{44}$ However, it was also proposed that materials of low surface energy and low critical surface tension are less prone to biofouling and have better fouling-release potential. ${ }^{25}$ Polar surfaces that become highly hydrated upon contact with aqueous media have been shown to be less prone to biofouling. ${ }^{43}$ The polymers discussed in this study have very similar water wettability, with static contact angles ranging from 96 to 115 degrees (see the Supporting Information for details; Figure S3 and Table S1). The static and dynamic contact angles of four different liquids, namely diodomethane, glycerol, anhydrous hexadecane, and water, on smooth PDMS, PU, and PMMA samples were measured and, applying the Owens ${ }^{45}$ and Zisman's ${ }^{46}$ methods, the surface energies and critical surface tensions of the specimen materials were determined. The values obtained are shown in Table 1 . The low and rather similar values recorded confirm that the 
polymer surface energy per unit area is low and wettability is similar. ${ }^{46}$ However, it was previously shown that the marine settlement of, for example, the barnacle larvae (cyprids) depends on various surface parameters (e.g., type of surface functional groups, surface charge) and does not necessarily correlate with the Gibbs free energy. ${ }^{19-21,47-49}$ Laboratory studies suggest that cyprids preferentially settle on the negatively charged surfaces, and the least settlement was observed on positively charged substrates. On the other hand, under natural field conditions, biofilms form very quickly and after 10 days, the direct effect of surface charges are obliterated; ${ }^{50,51}$ although recent studies suggest that differences in surface properties may alter the biofilm community, ${ }^{52}$ which in turn interacts with invertebrate fouling. ${ }^{53}$ As confirmed by $\zeta$ potential measurements (Figure S4 in the Supporting Information) and the literature data (Table 1), under the experimental conditions all polymers used for pattern replication in this study have negatively charged surfaces but possess different functional groups exposed. Thus, the most significant difference between the tested materials and substrates may lie in the elastic modulus (Figure 3), which may be the dominant factor regulating fouling release, ${ }^{54}$ and fouling properties.

Multiway ANOVA analysis of the nanoindentation data showed that both the choice of the material and the surface patterning had significant effects on surface hardness and modulus values. PMMA samples were significantly harder and less elastic than PDMS and PU samples, regardless of the dimensions of the patterns. However, for PMMA, $3 \mu \mathrm{m}$ pillars were substantially harder than smooth or $5 \mu \mathrm{m}$ sized pillars, and $5 \mu \mathrm{m}$ pillars were less elastic than smooth or $3 \mu \mathrm{m}$ structures. No differences in hardness or elasticity between pattern dimensions were observed for PDMS or PU (Supporting Information, Tables S2 - S5).

Effect on Marine Growth. Under natural field conditions, a diversity of organisms interact with the surface. Biofilms and slimes containing EPS from bacteria and microalgae would be present soon after immersion in the sea. The dominant organisms present in our field test were spirorbid tubeworms. Little is known about the settlement behavior of spirorbid worms but evidence from studies of Hydroides elegans (from related subfamily) suggest that exploration of the surface and biofilms occurs before settlement. The larvae examine the surface by pressing their anterior pole against the surface. When a suitable surface is detected, the larvae tether themselves to the substratum with a mucous thread, then lie against the substratum and secrete an organic tube from the surface of their trunks to adhere to the substratum. ${ }^{55}$ It has also been demonstrated that after 10 days immersion biofilm communities developed similarly on surfaces of different wettabilities, and become equally attractive for settlement of Hydroides elegans. ${ }^{50}$

The results of the first and second immersion tests are shown in Figures 4-7. For clarity of presentation, we do not mark significance levels in the figures but briefly discuss them within the text. We provide details of statistical analysis of both immersion tests, including levels of significance, in the Supporting Information (Tables S6-S11). The dominant organisms present were calcareous tubeworms (Phylum Annelida, Class Polychaeta, Family Serpulidae). Other organisms include barnacles, sponges, and some bryozoans but these constituted $<1 \%$ of each sample.

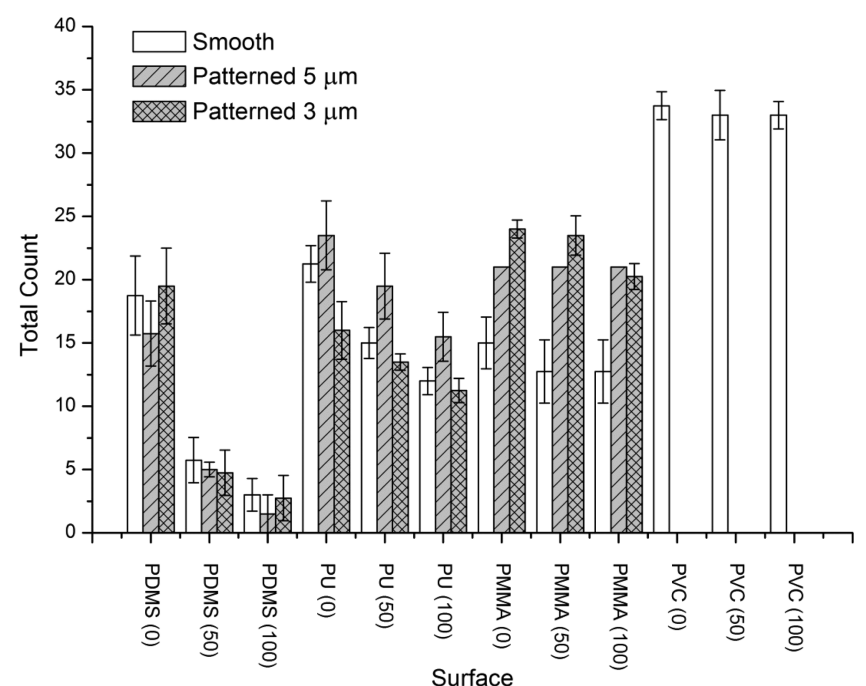

Figure 4. Results of the static field immersion test -1 st immersion. Figure shows mean values $( \pm$ SE) of total counts of organisms settled on smooth and patterned $(5 \mu \mathrm{m}+100 \mu \mathrm{m}$, and $3 \mu \mathrm{m}+100 \mu \mathrm{m}$ hierarchical structures) test samples after the first 2 weeks of immersion before $(0 \mathrm{psi})$ and after cleaning with water jet (50 and $100 \mathrm{psi}$, respectively). We note that, due to technical difficulties in pattern replication in PMMA, PMMA samples with $5 \mu \mathrm{m}$ pillars were tested as a single replicate only. PVC was used as an internal reference material.

Smooth samples of all polymers displayed similar performance when exposed to the static immersion tests, as shown by PDMS (0 psi), PU (0 psi), and PMMA (0 psi). This observation seems to corroborate our hypothesis that the surface elastic modulus sensed by the fouling organisms on smooth surfaces is similar for all three materials, and thus, there was no significant difference in material fouling performance when materials prior water jet cleaning were compared, as confirmed by the statistical analysis of the data (Supporting Information, Tables S6-S11). We note that the accumulation of biomass on patterned surfaces was higher compared to that on the smooth surfaces for substrates with lowest elasticity (PMMA) prior to water jet cleaning. This difference was more pronounced after the second immersion, prior to water jet cleaning.

The results shown in Figures 4 and 6 indicate that the removal of biomass from PDMS was the most efficient and was improved with increased pressure of the water jet, despite the fact that after the second immersion the surface fouling was significantly higher compared to the first immersion. Smooth and patterned PDMS samples fouled to the same extent, as confirmed by posthoc Tukey's multiple comparison test (Supporting Information, Tables S6-S11). There was no significant difference in retention of the accumulated biomass after water jet cleaning of smooth and patterned surfaces after the first immersion. This concurs with laboratory water jet tests reported in Chaudhury ${ }^{14}$ which showed no correlation in elastic modulus of PDMS to Ulva spores removal. However, after the second immersion the residue of the biomass after water jet cleaning was greater on the patterned surfaces as compared to the smooth ones. This could be explained by mechanical trapping of the biomass attached. The cleaning at maximum pressure after the second immersion resulted in restitution of the surface to the same state as after the cleaning following the first immersion and confirmed the reported fouling release 


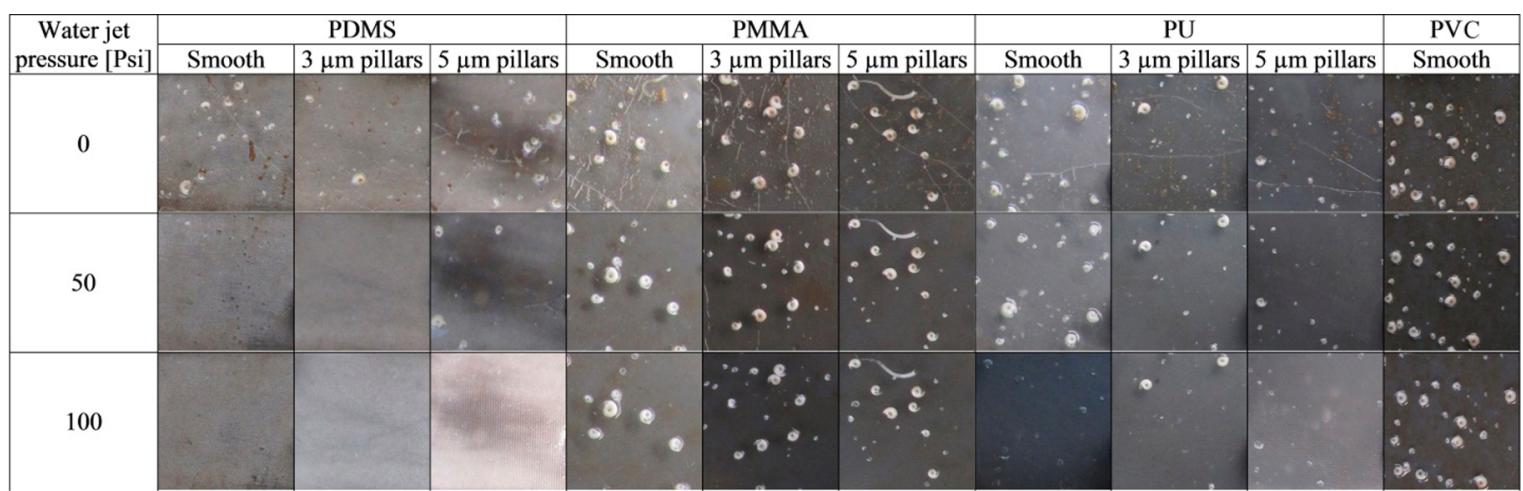

Figure 5. Results of the static field immersion test -1 st immersion. Table shows images of smooth and patterned $(5 \mu \mathrm{m}+100 \mu \mathrm{m}$, and $3 \mu \mathrm{m}+100$ $\mu \mathrm{m}$ hierarchical structures) test samples after the first 2 weeks of immersion before $(0 \mathrm{psi})$ and after cleaning with water jet $(50$ and 100 psi, respectively).

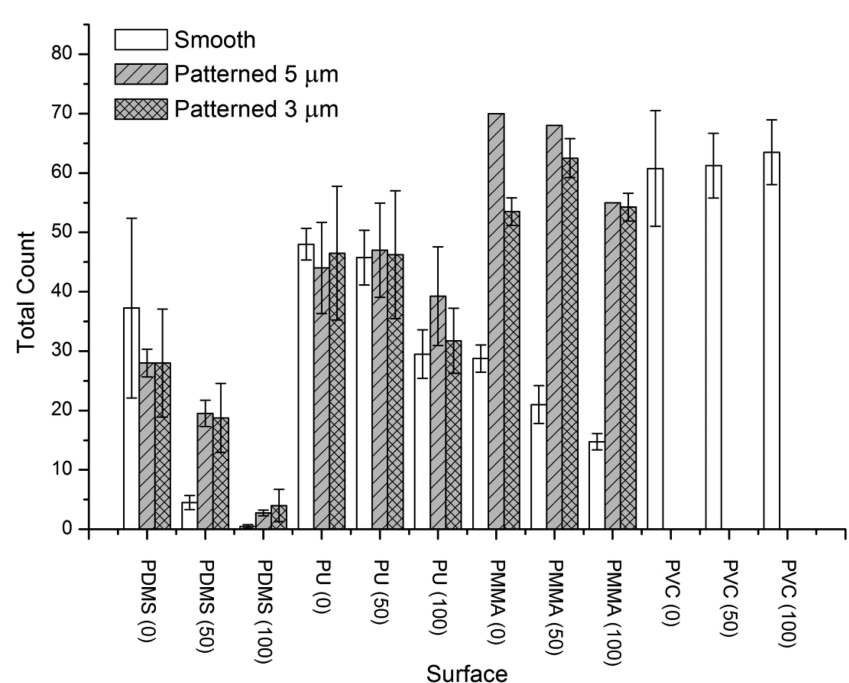

Figure 6. Results of the static field immersion test -2 nd immersion. Figure shows means $( \pm \mathrm{SE})$ of total count of organisms settled on smooth and patterned $(5 \mu \mathrm{m}+100 \mu \mathrm{m}$, and $3 \mu \mathrm{m}+100 \mu \mathrm{m}$ hierarchical structures) test samples after 2 weeks of the second immersion before ( 0 psi) and after cleaning with water jet (50 and 100 psi, respectively).

properties of PDMS. Similar trends were observed for PU samples, which possess similar elastic properties to the PDMS samples. Fouling removal from PU was, however, not as effective as from PDMS, and a significant amount of the material was retained on the surface after cleaning. The amount of the accumulated biomass increased after the second immersion and could not have been removed effectively.

Laboratory studies of the effect of surface topographies on marine larval settlement have demonstrated a good correlation between larvae size in relation to topographic features. ${ }^{32}$ However, under natural field conditions, microfouling inadvertently precedes settlement of invertebrates, overlaying additional complexity (physical and biological) to the surface. In addition, dynamic flow patterns over different surfaces further modulates settlement behaviors as well as natural detachment of organisms in the field. Field data from Vucko et al. ${ }^{56}$ indicated a lower settlement of tubeworms on microtopographies between 20 to $600 \mu \mathrm{m}$. In this study, we demonstrate that microtopography did not reduce fouling and, depending on the mechanical properties of the material, may instead facilitate biomass accumulation over time.

Fouling Removal. From the data shown, it is clearly visible that the effects of the surface microtopography are highly dependent on the choice of the polymeric material used. This finding was confirmed with posthoc statistical data analysis where "material vs. pattern" interactions were found to be significant for both immersion tests. For smooth substrates, PDMS performed best, followed by PMMA and PU. However, both 3 and $5 \mu \mathrm{m}$ pillars strongly decreased the antifouling performance of hard PMMA making those samples the worst performing patterned materials among all samples. We can

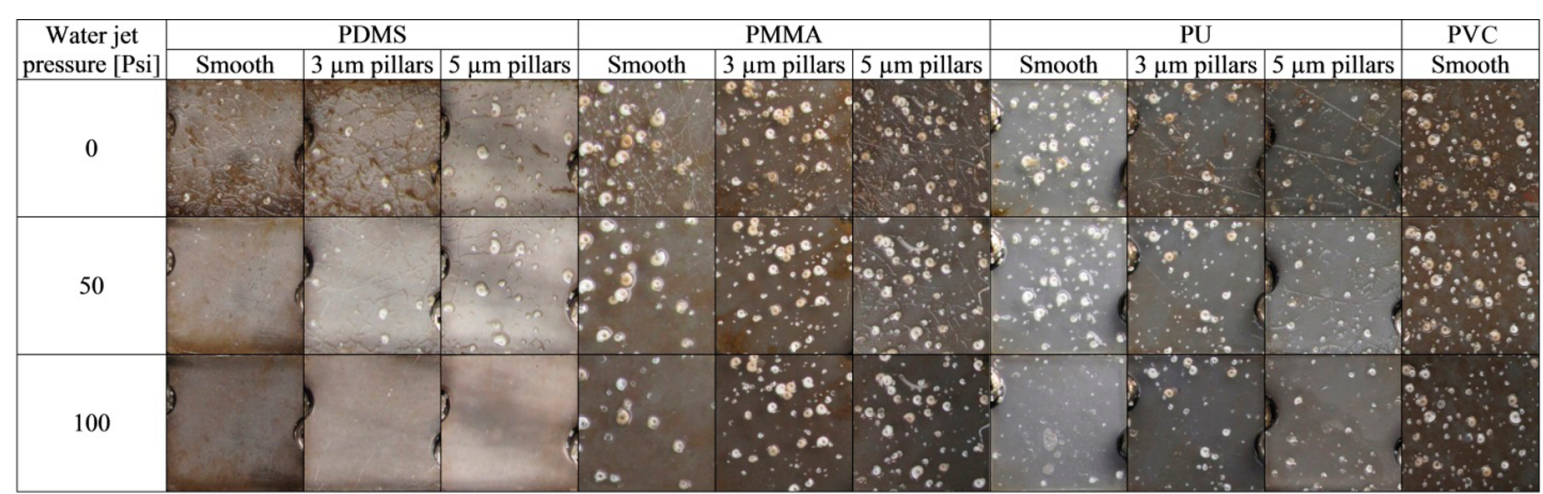

Figure 7. Results of the static field immersion test $-2 \mathrm{nd}$ immersion. Table shows images of smooth and patterned $(5 \mu \mathrm{m}+100 \mu \mathrm{m}$, and $3 \mu \mathrm{m}+100$ $\mu \mathrm{m}$ hierarchical structures) test samples after 2 weeks of the second immersion before $(0 \mathrm{psi})$ and after cleaning with water jet (50 and 100 psi, respectively). 
speculate that the hard (PMMA) patterns help in establishing stable attachment for the organisms and allow for mechanical accumulation of the biomass, particularly during the water jet cleaning.

\section{CONCLUSION}

In this study, we examined micropatterned surfaces in the natural marine environment and report the response of marine calcareous tubeworms to patterned surfaces. Our experiments show that surfaces with higher elastic modulus and hardness are more prone to fouling and have relatively inferior fouling release properties.

We argued that, in the absence of biologically active substances, the mechanical properties of the substrate in relation to fouling adhesion should play a larger role in fouling accumulation than surface chemistry under natural field conditions. The discussed polymers have significantly different hardness and modulus (Figure 3), and it has been proposed that at least some fouling organisms are sensitive to the modulus of the surface, ${ }^{15}$ whereas the attachment of others remains unaffected. ${ }^{18}$ Indeed, we observed the most significant accumulation of biomass on surfaces with the highest modulus (PMMA), but there was no significant effect of the applied surface patterning on surface modulus. The patterns on PMMA surfaces may have enhanced retention of the biomass at the surface (Figures 4 and 6) due to mechanical trapping of the biomass between the small surface features. We have also not observed significant effects of surface patterning on the biomass retention on PDMS and PU samples. It would appear that the mechanical properties of the materials, and in particular surface elastic modulus, are important to determine the susceptibility and fouling retention of the surface, in addition to the chemical composition of the materials.

The influence of the chemistry on fouling remains an important contributor, and a successful antifouling strategy must encompass a combination of mechanical and chemical factors. It is best illustrated by multiple antifouling strategies applied by fouling-free organisms, like $M$. hardwickii, in which surface topography, surface chemical composition, cellular excretions, as well as other micoroorganisms may play a role. More studies to understand the behaviors of micropatterned surfaces in the natural environment, subject to factors such as hydrodynamic shear, biofilms, and chemical cues, is needed. Understanding of the mechanisms underlying the observed effect of surface modulus on the exploration and settlement, as well as of the effect of the patterning on the sensed modulus, will require much more detailed and systematic studies.

\section{ASSOCIATED CONTENT}

\section{S Supporting Information}

The Supporting Information is available free of charge on the ACS Publications website at DOI: 10.1021/acsami.6b14262.

Fabrication of patterned surfaces, laboratory assays, and statistical analysis. (PDF)

\section{AUTHOR INFORMATION}

\section{Corresponding Authors}

*E-mail: dominik.janczewski@ch.pw.edu.pl. Tel: +48 22234 5583. Fax: +4822 2345504.

*E-mail: tmsteolm@nus.edu.sg. Tel: +65 6774 9887. Fax: +65 67761455
*E-mail: g.j.vancso@utwente.nl. Tel.: +31 53489 2974. Fax: +31534893823.

\section{ORCID}

Dominik Jańczewski: 0000-0002-5466-6444

G. Julius Vancso: 0000-0003-4718-0507

\section{Author Contributions}

The manuscript was written through contributions of all authors. All authors have given approval to the final version of the manuscript.

\section{Notes}

The authors declare no competing financial interest.

\section{ACKNOWLEDGMENTS}

We gratefully acknowledge Zhu Xiaoying from Patterning and Fabrication Group of the Institute of Materials Research and Engineering (IMRE), Singapore, for his help with $\zeta$-potential measurements and Shen Lu and Augustine Cheong from the SERC Nanofabrication, and Characterisation (SNFC) facility at IMRE for their help with nanoindentation. We are grateful to the Agency for Science, Technology and Research (A*STAR), Singapore, for providing financial support for internship students S.M. and R.G.Z.R. This research was financially supported by the IMAS program of SERC, Singapore.

\section{ABBREVIATIONS}

ANOVA, analysis of variance

DI (water), deionized (water)

FDTS, perfluorodecyltrichlorosilane

PDMS, polydimethylsiloxane

PMMA, poly(methyl methacrylate)

$\mathrm{PU}$, polyurethane

TMSI, Tropical Marine Science Institute

\section{REFERENCES}

(1) Bott, T. R. Industrial Biofouling; Elsevier: Kidlington, Oxford, U.K., 2011.

(2) Cooksey, K.; Murthy, P. S.; Flemming, H.-C.; Venkatesan, R. Marine and Industrial Biofouling; Springer: Berlin, 2009.

(3) Thomason, J.; Wiley, I.; Dürr, S. Biofouling; Wiley-Blackwell: Chichester, U.K., 2010.

(4) Callow, J. A.; Callow, M. E. Trends in the Development of Environmentally Friendly Fouling-Resistant Marine Coatings. Nat. Commun. 2011, 2, 244.

(5) Magin, C. M.; Cooper, S. P.; Brennan, A. B. Non-Toxic Antifouling Strategies. Mater. Today 2010, 13, 36-44.

(6) Konstantinou, I. K.; Albanis, T. A. Worldwide Occurrence and Effects of Antifouling Paint Booster Biocides in the Aquatic Environment: A Review. Environ. Int. 2004, 30, 235-248.

(7) Lejars, M.; Margaillan, A.; Bressy, C. Fouling Release Coatings: A Nontoxic Alternative to Biocidal Antifouling Coatings. Chem. Rev. 2012, 112, 4347-4390.

(8) Ralston, E.; Swain, G. Bioinspiration-the Solution for Biofouling Control? Bioinspiration Biomimetics 2009, 4, 015007.

(9) Scardino, A. J.; de Nys, R. Mini Review: Biomimetic Models and Bioinspired Surfaces for Fouling Control. Biofouling 2011, 27, 73-86.

(10) Scardino, A. J.; Hudleston, D.; Peng, Z.; Paul, N. A.; de Nys, R. Biomimetic Characterisation of Key Surface Parameters for the Development of Fouling Resistant Materials. Biofouling 2009, 25, 83-93.

(11) Brzozowska, A. M.; Parra-Velandia, F. J.; Quintana, R.; Zhu, X.; Lee, S. C. S.; Lim, C.-S.; Janczewski, D.; Teo, L.-M. S.; Vancso, J. Biomimicking Micropatterned Surfaces and Their Effect on Marine Biofouling. Langmuir 2014, 30, 9165-9175. 
(12) Flemming, H.-C.; Murthy, P. S.; Venkatesan, R.; Cooksey, K. Marine and Industrial Biofouling; Springer: Berlin, 2009; Vol. 4.

(13) Aldred, N.; Scardino, A.; Cavaco, A.; de Nys, R.; Clare, A. S. Attachment Strength Is a Key Factor in the Selection of Surfaces by Barnacle Cyprids (Balanus Amphitrite) During Settlement. Biofouling 2010, 26, 287-299.

(14) Chaudhury, M. K.; Finlay, J. A.; Chung, J. Y.; Callow, M. E.; Callow, J. A. The Influence of Elastic Modulus and Thickness on the Release of the Soft-Fouling Green Alga Ulva Linza (Syn. Enteromorpha Linza) from Poly(Dimethylsiloxane) (Pdms) Model Networks. Biofouling 2005, 21, 41-48.

(15) Gray, N. L.; Banta, W. C.; Loeb, G. I. Aquatic Biofouling Larvae Respond to Differences in the Mechanical Properties of the Surface on Which They Settle. Biofouling 2002, 18, 269-273.

(16) Guardiola, F. A.; Cuesta, A.; Meseguer, J.; Esteban, M. A. Risks of Using Antifouling Biocides in Aquaculture. Int. J. Mol. Sci. 2012, 13, $1541-1560$.

(17) Sun, Y. J.; Guo, S. L.; Walker, G. C.; Kavanagh, C. J.; Swain, G. W. Surface Elastic Modulus of Barnacle Adhesive and Release Characteristics from Silicone Surfaces. Biofouling 2004, 20, 279-289.

(18) Ahmed, N.; Murosaki, T.; Kakugo, A.; Kurokawa, T.; Gong, J. P.; Nogata, Y. Long-Term in Situ Observation of Barnacle Growth on Soft Substrates with Different Elasticity and Wettability. Soft Matter 2011, 7, 7281-7290.

(19) Guo, S.; Puniredd, S. R.; Jańczewski, D.; Lee, S. S. C.; Teo, S. L. M.; He, T.; Zhu, X.; Vancso, G. J. Barnacle Larvae Exploring Surfaces with Variable Hydrophilicity: Influence of Morphology and Adhesion of "Footprint" Proteins by Afm. ACS Appl. Mater. Interfaces 2014, 6, 13667-13676.

(20) Petrone, L.; Di Fino, A.; Aldred, N.; Sukkaew, P.; Ederth, T.; Clare, A. S.; Liedberg, B. Effects of Surface Charge and Gibbs Surface Energy on the Settlement Behaviour of Barnacle Cyprids (Balanus Amphitrite). Biofouling 2011, 27, 1043-1055.

(21) Zhu, X.; Jańczewski, D.; Lee, S. S. C.; Teo, S. L.-M.; Vancso, G. J. Cross-Linked Polyelectrolyte Multilayers for Marine Antifouling Applications. ACS Appl. Mater. Interfaces 2013, 5, 5961-5968.

(22) Bers, A. V.; Wahl, M. The Influence of Natural Surface Microtopographies on Fouling. Biofouling 2004, 20, 43-51.

(23) Granhag, L. M.; Finlay, J. A.; Jonsson, P. R.; Callow, J. A.; Callow, M. E. Roughness-Dependent Removal of Settled Spores of the Green Alga Ulva (Syn. Enteromorpha) Exposed to Hydrodynamic Forces from a Water Jet. Biofouling 2004, 20, 117-122.

(24) Schumacher, J. F.; Carman, M. L.; Estes, T. G.; Feinberg, A. W.; Wilson, L. H.; Callow, M. E.; Callow, J. A.; Finlay, J. A.; Brennan, A. B. Engineered Antifouling Microtopographies - Effect of Feature Size, Geometry, and Roughness on Settlement of Zoospores of the Green Alga Ulva. Biofouling 2007, 23, 55-62.

(25) Brady, J. Properties Which Influence Marine Fouling Resistance in Polymers Containing Silicon and Fluorine. Prog. Org. Coat. 1999, $35,31-35$.

(26) Brady, R. F. A Fracture Mechanical Analysis of Fouling Release from Nontoxic Antifouling Coatings. Prog. Org. Coat. 2001, 43, 188192.

(27) Krol, P. Polyurethanes - a Review of 60 Years of Their Syntheses and Applications. Polimery 2009, 54, 489-500.

(28) Council, C.-T. E. C. I. Pmma Applications. http://www.pmmaonline.eu/applications.

(29) Cooper, S. P.; Finlay, J. A.; Cone, G.; Callow, M. E.; Callow, J. A.; Brennan, A. B. Engineered Antifouling Microtopographies: Kinetic Analysis of the Attachment of Zoospores of the Green Alga Ulva to Silicone Elastomers. Biofouling 2011, 27, 881-891.

(30) Decker, J. T.; Sheats, J. T.; Brennan, A. B. Engineered Antifouling Microtopographies: Surface Pattern Effects on Cell Distribution. Langmuir 2014, 30, 15212-15218.

(31) Halder, P.; Nasabi, M.; Jayasuriya, N.; Shimeta, J.; Deighton, M.; Bhattacharya, S.; Mitchell, A.; Bhuiyan, M. A. An Assessment of the Dynamic Stability of Microorganisms on Patterned Surfaces in Relation to Biofouling Control. Biofouling 2014, 30, 695-707.
(32) Schumacher, J. F.; Aldred, N.; Callow, M. E.; Finlay, J. A.; Callow, J. A.; Clare, A. S.; Brennan, A. B. Species-Specific Engineered Antifouling Topographies: Correlations between the Settlement of Algal Zoospores and Barnacle Cyprids. Biofouling 2007, 23, 307-317. (33) Schumacher, J. F.; Long, C. J.; Callow, M. E.; Finlay, J. A.; Callow, J. A.; Brennan, A. B. Engineered Nanoforce Gradients for Inhibition of Settlement (Attachment) of Swimming Algal Spores. Langmuir 2008, 24, 4931-4937.

(34) Peter, Z.; Paul, A. G.; John, D. S.-S. Functional Polymeric Coatings: Synthesis, Properties, and Applications. In Research Perspectives on Functional Micro- and Nanoscale Coatings; Ana, Z., Maria Carmen, M.-M., Eds.; IGI Global: Hershey, PA, 2016; pp 78104.

(35) Crisp, D. J.; Walker, G.; Young, G. A.; Yule, A. B. Adhesion and Substrate Choice in Mussels and Barnacles. J. Colloid Interface Sci. 1985, 104, 40-50.

(36) Phang, I. Y.; Aldred, N.; Clare, A. S.; Vancso, G. J. Towards a Nanomechanical Basis for Temporary Adhesion in Barnacle Cyprids (Semibalanus Balanoides). J. R. Soc., Interface 2008, 5, 397-401.

(37) Hadfield, M. G.; Nedved, B. T.; Wilbur, S.; Koehl, M. A. R. Biofilm Cue for Larval Settlement in Hydroides Elegans (Polychaeta): Is Contact Necessary? Mar. Biol. 2014, 161, 2577-2587.

(38) Underwood, A. J. Experiments in Ecology: Their Logical Design and Interpretation Using Analysis of Variance; Cambridge University Press: New York, 1997.

(39) Falahati, H.; Wong, L.; Davarpanah, L.; Garg, A.; Schmitz, P.; Barz, D. P. J. The Zeta Potential of Pmma in Contact with Electrolytes of Various Conditions: Theoretical and Experimental Investigation. Electrophoresis 2014, 35, 870-882.

(40) Chen, H.; Song, W.; Zhou, F.; Wu, Z. K.; Huang, H.; Zhang, J. H.; Lin, Q.; Yang, B. The Effect of Surface Microtopography of Poly(Dimethylsiloxane) on Protein Adsorption, Platelet and Cell Adhesion. Colloids Surf., B 2009, 71, 275-281.

(41) Palacio, M. L. B.; Bhushan, B. Bioadhesion: A Review of Concepts and Applications. Philos. Trans. R. Soc., A 2012, 370, 23212347.

(42) Rath, S.; Chavan, J.; Sasane, S.; Jagannath; Patri, M.; Samui, A.; Chakraborty, B. Two Component Silicone Modified Epoxy Foul Release Coatings: Effect of Modulus, Surface Energy and Surface Restructuring on Pseudobarnacle and Macrofouling Behavior. Appl. Surf. Sci. 2010, 256, 2440-2446.

(43) Yang, W. J.; Neoh, K.-G.; Kang, E.-T.; Lee, S. S. C.; Teo, S. L.M.; Rittschof, D. Functional Polymer Brushes Via Surface-Initiated Atom Transfer Radical Graft Polymerization for Combating Marine Biofouling. Biofouling 2012, 28, 895-912.

(44) Holm, E. R.; Cannon, G.; Roberts, D.; Schmidt, A. R.; Sutherland, J. P.; Rittschof, D. The Influence of Initial Surface Chemistry on Development of the Fouling Community at Beaufort, North Carolina. J. Exp. Mar. Biol. Ecol. 1997, 215, 189-203.

(45) Owens, D. K.; Wendt, R. C. Estimation of the Surface Free Energy of Polymers. J. Appl. Polym. Sci. 1969, 13, 1741-1746.

(46) Zisman, W. A. Relation of the Equilibrium Contact Angle to Liquid and Solid Constitution. In Contact Angle, Wettability, and Adhesion, 43rd ed.; American Chemical Society: Washington, DC, 1964; pp 1-51.

(47) Zhu, X.; Jańczewski, D.; Guo, S.; Lee, S. S. C.; Parra Velandia, F. J.; Teo, S. L.-M.; He, T.; Puniredd, S. R.; Vancso, G. J. Polyion Multilayers with Precise Surface Charge Control for Antifouling. ACS Appl. Mater. Interfaces 2015, 7, 852-861.

(48) Kamino, K. Underwater Adhesive of Marine Organisms as the Vital Link between Biological Science and Material Science. Mar. Biotechnol. 2008, 10, 111-121.

(49) Kamino, K. Mini-Review: Barnacle Adhesives and Adhesion. Biofouling 2013, 29, 735-749.

(50) Huggett, M. J.; Nedved, B. T.; Hadfield, M. G. Effects of Initial Surface Wettability on Biofilm Formation and Subsequent Settlement of Hydroides Elegans. Biofouling 2009, 25, 387-399.

(51) Yandi, W.; Mieszkin, S.; di Fino, A.; Martin-Tanchereau, P.; Callow, M. E.; Callow, J. A.; Tyson, L.; Clare, A. S.; Ederth, T. 
Charged Hydrophilic Polymer Brushes and Their Relevance for Understanding Marine Biofouling. Biofouling 2016, 32, 609-625.

(52) Dang, H.; Lovell, C. R. Microbial Surface Colonization and Biofilm Development in Marine Environments. Microbiol. Mol. Biol. Rev. 2016, 80, 91-138.

(53) Zardus, J. D.; Nedved, B. T.; Huang, Y.; Tran, C.; Hadfield, M. G. Microbial Biofilms Facilitate Adhesion in Biofouling Invertebrates. Biol. Bull. 2008, 214, 91-8.

(54) Brady, R. F.; Singer, I. L. Mechanical Factors Favoring Release from Fouling Release Coatings. Biofouling 2000, 15, 73-81.

(55) Hadfield, M. G. Biofilms and Marine Invertebrate Larvae: What Bacteria Produce That Larvae Use to Choose Settlement Sites. Ann. Rev. Marine Sci. 2011, 3, 453 10.1146/annurev-marine-120709142753.

(56) Vucko, M. J.; Poole, A. J.; Sexton, B. A.; Glenn, F. L.; Carl, C.; Whalan, S.; de Nys, R. Combining a Photocatalyst with Microtopography to Develop Effective Antifouling Materials. Biofouling 2013, 29, 751-762. 